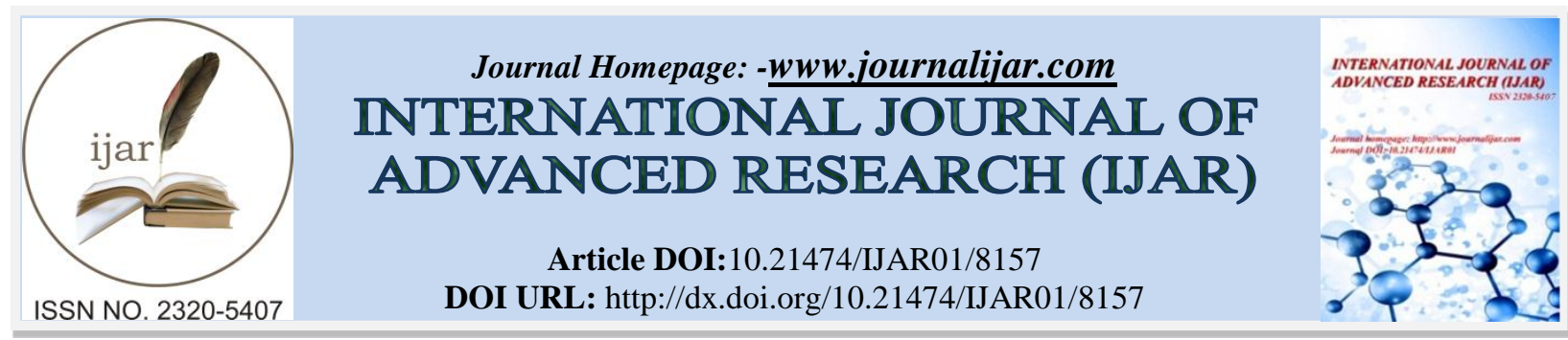

RESEARCH ARTICLE

\title{
STUDY AND MODELING OF THE OPERATION OF A SOLAR WATER HEATER IN TOGO.
}

Komi A. Amou, Yendoube Lare, Koffi Sagna, Niyem M. Bawana and Kossi Napo. Laboratoryon Solar Energy, Physics Department, Sciences Faculty, University of Lome, Lomé,Togo.

\section{Manuscript Info}

\section{Manuscript History}

Received: 04 October 2018

Final Accepted: 06 November 2018

Published: December 2018

\section{Keywords:-}

Solar energy, Solar collector, Temperature, Thermosiphon, Simulation

\begin{abstract}
The work presented concerns the analysis of the behavior of a flat water solar collector. Mathematical modeling, based on the global energy balance method, takes into account the initial conditions associated with the sensor. This modeling uses an estimate of the evolution of global solar flux. The model's resolution was made under a Matlab environment. The results of the numerical simulation make it possible to compare the temperature of the water at the output of the sensor as well as the power measured at the simulated values. The results obtained show that the model is valid and can predict the performance of the solar water heater. These results also show that the regression coefficient $\mathrm{R}^{2}$ is about 0.9 which is very interesting. This model can therefore be used to describe the performance of a solar collector in Togo.
\end{abstract}

Copy Right, IJAR, 2018. All rights reserved.

\section{Introduction:-}

Nowadays, the environmental problems created by the use of conventional energy sources have led researchers to look for other sources of clean energy, especially solar energy. The use of solar energy begins with its conversion in photovoltaic or thermal form. From the thermal point of view, the solar energy received by the collector plane is partially transformed into heat energy. For electrical conversion, a part of the solar energy collected on the receiver plane is transformed into electricity. The most successful conversion remains that in thermal energy seen its simplicity of installation and its wide field of use. Solar thermal systems are used in various solar applications such as, the drying of grains or wood, the heating of industrial or residential premises, the elimination of microbes in water as well as in solar refrigeration. The rapid evolution of modern solar power processes has led to the development of several types of solar water heater systems such as flat solar collectors, vacuum tube collectors and cylindro parabolic concentrators. In this study, we are particularly interested in flat water solar collectors. These transform the radiant energy of the sun into thermal energy extracted by water in flow in the sensor. Several types of water sensors have been built and tested around the world. The main goal is to collect the maximum amount of solar energy at a minimum cost. The characterization of solar installations in terms of performance, reliability and sustainability is a necessity to support the development of a quality solar offer. The most common technologies are: planar unglazed collectors, glazed collectors and vacuum collectors. Unglazed sensors made of black polymer plastic are low cost, but with a problem of wind sensitivity and convection loss. This problem is lessened for sensors with glazing or double glazing. In contrast, vacuum tube solar collectors capture solar energy well and their thermal losses to the environment are extremely low. This study focuses only on flat glass collectors. In this article, the mathematical model is that of Duffie et al. (1980). The flat thermal sensor has been used for its simplicity. A Matlab code was then developed based on the work of Hartwig et al. (2010) to estimate the flow of useful energy and the temperature of the fluid at the outlet of the glazed plane sensor as well as the efficiency of the sensor. A validation

Corresponding Author:-Komi A. Amou. 
experiment was then carried out on the site of the Solar Energy Laboratory of the University of Lomé. Simulation and experimental results are compared and discussed.

\section{Equipments:-}

\section{Description of the sensor used:-}

The flat water solar collector, object of the study is essentially composed of:

1. transmitter).

2.

3.

4.

- Ins

5. Envelope to cover all previous components and protect them from dust and moisture.

The characteristics of the sensor are presented in Table 1.

Table1:-Caracteristics of the solar heater

\begin{tabular}{|l|l|}
\hline escription & etails \\
\hline ze & $61 \mathrm{~m}^{2}$ \\
\hline eight & $\mathrm{kg}$ \\
\hline ature of the absorber & iivre \\
\hline ature of the chassis & uminium \\
\hline polant & ter \\
\hline ssorbency & 95 \\
\hline nissivity & 5 \\
\hline ansmittance & 96 \\
\hline max & $36 \mathrm{~L}$ \\
\hline $\mathrm{x}$ & $89 \mathrm{~kW}$ \\
\hline ax & $66^{\circ} \mathrm{C}$ \\
\hline rial number & $\mathrm{bar}$ \\
\hline brication date & 552 \\
\hline
\end{tabular}

\section{Other materials:-}

Other materials are used for the measurement of different parameters as:

1. Type $\mathrm{K}$ and $\mathrm{E}$ thermocouples for measuring inlet and outlet water temperatures.

2. AnAhlbornpyranomètre

3. A central data acquisition (Almemo)

4. A computer for data processing and matlabmodelling

\section{Mathematical modelling:- \\ Modeling hypotheses:-}

Part of the absorbed energy is transferred to the coolant and induces an increase in temperature in the $\mathrm{x}$ and $\mathrm{y}$ directions. In order to obtain a mathematical description of the temperature profiles with a minimum of energy losses, we have emitted the following hypotheses inspired by J. A.Duffie (1980):

1. The temperature gradient across the window is negligible;

2. The heat transfer is one-dimensional;

3. Energy is not stored in the glass;

4. The window is opaque to infra-red radiation;

5. The sky is considered a black body for long-wave radiation;

6. The temperature gradient in the direction of the heat flow and between the tubes can be processed independently;

7. The properties and physical quantities are independent of the temperature;

8. Front and back losses are achieved at equal temperatures;

9. Dirt and dust on the sensor are assumed to be negligible;

10. Shading on the sensor is assumed to be negligible;

11. Solar collector has the advantage of absorbing the diffuse and direct components of irradiation. 


\section{Modeling:-}

Solar irradiation goes from the visible spectrum to the infra-red $(0.3 \mu \mathrm{m}$ to $25 \mu \mathrm{m})$. The study of solar thermal energy for specific thermal applications begins with the estimation of the solar constant $\mathrm{G}_{\mathrm{sc}}$. It is the solar energy per unit of time received by a unit area perpendicular to the direction of propagation of the incident rays, at the mean Earth-Sun distance out of the atmosphere. Given metrological methods for estimating $\mathrm{G}_{\mathrm{sc}}=1367 \mathrm{Wm}^{-2}$ with an uncertainty of about 1\% (J. A. Duffie (1980) and A. C. Yunus, (2015)). However, the variations of the Earth-Sun distance induce a greater uncertainty of the order of $\mp 3 \%$. To take this variation into account, the following equation is used to calculate the solar constant received.

$$
G_{\text {on }}=G_{s c}\left[1+0,033 \cos \left(\frac{360 s}{365}\right)\right]
$$

Where $\mathrm{G}_{o n}$ is the value of the solar constant on a plane normal to irradiation at day $\mathrm{n}$ of the year with the 1 st of January as day 1 .

\section{Sensor orientation:-}

The total energy collected by the sensor depends on variables such as the season, the period of exposure of the sensor, the azimuth angle and especially the inclination of the sensor.In order to obtain the maximum useful energy, it is very important to optimize thechoice of the variables defined previously. It is therefore possible to orient the sensor according to the seasons. To collect as much energy as possible, the ideal position of the sensor is that for which it is tilted at an angle equal to the altitude of the place by J. A. Duffie and W. A. Beckman (1980).

\section{Optical characteristics:-}

Solar irradiation and the optical properties of materials are intimately linked. Thus, the absorptivity ( $\alpha$ ), the emissivity $(\varepsilon)$ and the reflectivity $(\rho r)$ are the main properties of the materials taken into account during the manufacture of flat thermal sensors. These quantities were calculated by Duffie [1].

$\alpha=\frac{\int_{0}^{\infty} \alpha \lambda G \lambda i d \lambda}{\int_{0}^{\infty} G \lambda, i d \lambda}$

$\varepsilon=\frac{1}{E \lambda, b} \int_{0}^{\infty} E_{\lambda} E_{\lambda, b} d \lambda$

$\rho r=\frac{\int_{0}^{\infty} G \lambda d \lambda}{\int_{0}^{\infty} G_{i} d \lambda}$

\section{Flat solar collectormodelization:-}

In a steady state, the useful energy flux is the energy flow absorbed by the heat transfer liquid minus the direct or indirect heat losses with the surrounding medium. The useful energy flow thus calculated with the following formula by H. Taherian et al. (2011) and F. Mosallat et al. (2013):

$$
q_{u}=A_{c}\left[I_{g} \tau \alpha-U_{g}\left(T_{i}-T_{a}\right)\right]=m C_{p}\left(T_{s}-T_{e}\right)
$$

An approximation of $q_{u}$ can be obtained by replacing the average temperature of the solar collector by the inlet temperature $\mathrm{T}_{i}$ of the coolant, we obtain the equation:

$q_{u}=A_{c} F_{R}\left[I_{g} \tau \alpha-U_{g}\left(T_{i}-T_{a}\right)\right]$

with $\mathrm{F}_{\mathrm{R}}$ the overall coefficient of thermal losses.

$$
F_{R}=\frac{m c_{p}}{A_{c} U_{g}}\left[1-\exp \left(\frac{U_{g} F^{\prime} A_{c}}{m C_{p}}\right)\right]
$$

The parameter $\mathrm{F}^{\prime}$ is the efficiency factor of the glazed plane sensor. It can be calculated by considering a temperature distribution between two tubes of the solar collector absorber and assuming that the temperature gradient is negligible in the direction of flow. An energy balance as shown in Figure 1 applied to an element of width $\Delta x$ in the direction of the flow is written:

$$
\mathrm{S} \Delta x-U_{g} \Delta x\left(\mathrm{~T}-T_{a}\right)+\left[-\mathrm{k} \delta\left(\frac{d y}{d x}\right)_{x+d x}\right]=0
$$


The magnitude $\mathrm{S}$ represents the solar radiation absorbed.

By dividing the terms of equation 8 by $\Delta x$ and tending $\Delta x$ to zero we get:

$$
\frac{d^{2} T}{d x^{2}}=\frac{U_{g}}{k \delta}\left(T-T_{a}-\frac{s}{U_{g}}\right)
$$

The following boundary conditions are applied

$\left(\frac{d T}{d x}\right)_{x=0}=0,(T)_{x=\frac{W-D}{2}}=T_{b}$

with $\mathrm{W}$ the distance between the tubes, $\mathrm{D}$ is the diameter of the tubes and $\delta$ the thickness.

For reasons of simplification, the following variables are introduced:

$$
\begin{gathered}
m=\sqrt{\frac{U_{g}}{k \delta}} \\
\psi=T-T_{a}-\frac{s}{U_{g}}
\end{gathered}
$$

Thus, equation (9) becomes:

$\frac{d^{2} \psi}{d x^{2}}-m^{2} \psi=0$

Which has boundary conditions:

$\left(\frac{d \psi}{d x}\right)_{x=0}=0$ and $(\psi)_{x=L}=T_{b}-T_{1}-\frac{S}{U_{g}}$

Equation (12) is a linear homogeneous differential equation of second order whose general solution is:

$$
\psi=C_{1}^{\prime} \exp (m x)+C_{2}^{\prime} \exp (-m x)=C_{1} \sinh (m x)+C_{2} \cosh (m x)
$$

The first boundary condition leads to $\mathrm{C}_{1}=0$

and the second to:

$$
\psi=T_{b}-T_{a}-\frac{S}{U_{g}}=C_{2} \cosh (\mathrm{mL})
$$

with $T_{b} T_{a} \frac{\frac{s}{U_{g}}}{\cosh (m L)}, C_{1}$ and $C_{2}$ are known,

Equation (13) become: $\frac{T-T_{a}-\frac{s}{U_{g}}}{T_{b}-T_{a} \frac{s}{U_{g}}}=\frac{\cosh (m x)}{\cosh (m L)}$

This last equation gives the temperature profile in the $\mathrm{x}$ and $\mathrm{y}$ directions. The energy input by conduction in a tube area per unit length and in the direction of flow is then evaluated by applying the law of length and in the direction of flow is then evaluated by applying the Fourier's law:

$$
q_{\text {fin }}^{\prime}=-\mathrm{k} \delta\left(\frac{d T}{d x}\right)_{x=l}=\frac{k \delta m}{U_{g}}\left[\mathrm{~S}-U_{g}\left(T_{b}-T_{a}\right)\right] \tanh (\mathrm{mL})
$$

For both sides of the tube, the energy collected is: $q_{f i n}^{\prime}=(W-D)\left[S-U_{g}\left(T_{b}-T_{a}\right)\right] \frac{\tanh \left[\frac{m(w-D)}{2}\right]}{\frac{m(w-D)}{2}}$

Where Fis the efficiency.

$$
\begin{aligned}
& q_{\text {fin }}^{\prime}=(W-D)\left[S-U_{g}\left(T_{b}-T_{a}\right)\right] \\
& F=\frac{\tanh \left[\frac{m(w-D)}{2}\right]}{\frac{m(w-D)}{2}}
\end{aligned}
$$

The energy collected also includes the energy collected above the tube. This one is given by:

$$
q_{\text {tube }}^{\prime}=\mathrm{D}\left[\mathrm{S}-U_{g}\left(T_{b}-T_{a}\right)\right]
$$

Therefore, the useful energy in the direction of the flow is:

$$
q_{u}^{\prime}=q_{f i n}^{\prime}+q_{\text {tube }}^{\prime}=[(W-D) F+D]\left[S-U_{g}\left(T_{b}-T_{a}\right)\right]
$$

This energy will have to be transferred to the fluid and can be estimated according to the thermal resistances as follows: 


$$
q_{u}^{\prime}=\frac{T_{b}-T_{a}}{\frac{1}{h_{f i \pi D_{i}}}+\frac{1}{C_{p}}}
$$

With $C_{b}=\frac{k_{b} b}{\gamma}(23)$ which is the conductivity

Solving the equation (22) for the variable $T_{b}$ and introducing it in equation (23) the resolution of the result for the useful energy gives:

$q_{u}^{\prime}=\mathrm{WF}^{\prime}\left[\mathrm{S}-U_{g}\left(T_{f}-T_{a}\right)\right]$
Where $\quad F^{\prime}=\frac{\frac{1}{U_{g}}}{W\left[\frac{1}{U_{g}[D+(W+D) F]}+\frac{1}{C_{b}}+\frac{1}{D_{i}^{h} h i}\right]} \quad$ (25)

physical interpretation of the coefficient $\mathrm{F}$ 'is that it is the ratio of the useful energy actually collected by the useful energy that should be collected if the absorption surface of the CPVwas at the temperature of the coolant.It should be noted that the denominator of equation (19) represents the thermal resistances of the fluid to the ambient air. This resistance can be noted $\frac{1}{U_{0}}$. Thus, $F^{\prime}$ is written as

$F^{\prime}=\frac{U_{0}}{U_{g}}$

(26) $F^{\prime}$ is the overall loss coefficient

$$
U_{g}=U_{a v}+U_{a r}+U_{i t}
$$

The losses from above are evaluated by the relation:

Where:

$$
U_{a v}=\frac{\frac{1}{N_{g}}}{\frac{C}{T_{p}}\left[\frac{T_{a v}-T_{a}}{N_{g}+f}\right]^{0,33}+\frac{1}{h_{w}}}+\frac{\sigma\left(T_{a v}^{2}+T_{a}^{2}\right)+\left(T_{a v}+T_{a}\right)}{\frac{1}{\varepsilon_{p}+0,05 N_{g}\left(1-\varepsilon_{p}\right)}+\frac{2 N_{g+f-1}}{\varepsilon_{g}}-N_{g}}
$$

$$
\begin{aligned}
& h_{w}=5,7+3,8 w \\
& f=\left(1-0,04 h_{w}+0,0005 h_{w}^{2}\right)\left(1+0,091 N_{g}\right) \\
& c=365,9(1-0,00883 \beta+0,0001298 \beta 2)
\end{aligned}
$$

and $\mathrm{T}_{\mathrm{p}}$ is the temperature of the absorber when the flow is zero and is obtained by:

$$
T_{p}=\frac{I_{g}(\tau \alpha)}{U_{g}}+T_{a}
$$

Finally, the solar collector's yield is obtained by Endalew [12] by dividing $q_{u}$ by $\left(I_{g} A_{c}\right)$. So,

$$
\eta=F_{R}\left[\tau \alpha-\frac{U_{g}\left(T_{i}-T_{a}\right)}{I_{g}}\right]
$$

A representation of the efficiency $\eta$ as a function of the parameter $\left(\frac{T_{i}-T_{a}}{I_{g}}\right)$ is linear as long as $U_{g}$ remains a constant [13].

Mathematical model of thermosiphon solarwater heater:-

Thermosiphon means that the circulation of heat passes by sensors to the balloon naturally without pump or other device, thanks to the difference of temperature (F. Yettou et al. (2008) and H. Taherian et al. (2011)). To do this, the balloon must imperatively be placed higher than the sensors. The studied system includes a storage tank, a glazed planter and provides domestic hot water during its operation. The thermal balance at the balloon is writtenby $\mathrm{F}$. Mosallat et al. (2013), Y. A. Cengel and M. A. Boles (1994) and Y. A. Boles (2006):

$$
\left(M C_{p}\right)_{s} \frac{d T_{s t}}{d t}=Q_{u}-Q_{t}-L_{p}
$$

With $L_{p}$ the charge or withdrawal of hot water, Qu the useful energy transmitted to the fluid and Qtthe thermal losses from the balloon to the ambient environment. The + in equation 2 indicates that the threshold sunshine condition is reached: 


$$
Q_{u}=A_{c} F_{R}\left[(\tau \alpha)_{e} I_{g}-U_{g}\left(T_{i}-T_{a}\right)\right]^{+}
$$

The daily variation of the storage temperature as a function of time is given by the relation:-

$$
T_{s t}(i+1)=T_{s t}+\frac{\Delta t}{\left(M C_{p}\right)_{s}}\left\{A_{c} F_{R}\left[S(i)-U_{g}\left(T_{i}(i)-T_{a}(i)\right)\right]^{+}-(U A)_{s t}\left(T_{s t}(i)-T_{a}(i)\right)\right\}
$$

Equation (3) shows that the temperature in the storage tank is not uniform but is treated. For balloons of reduced dimensions, it is assumed that this storage temperature is homogeneous.

\section{Simulation procedure:-}

The flowchart in Figure 1 illustrates the steps taken to perform the simulations of our solar heater system.

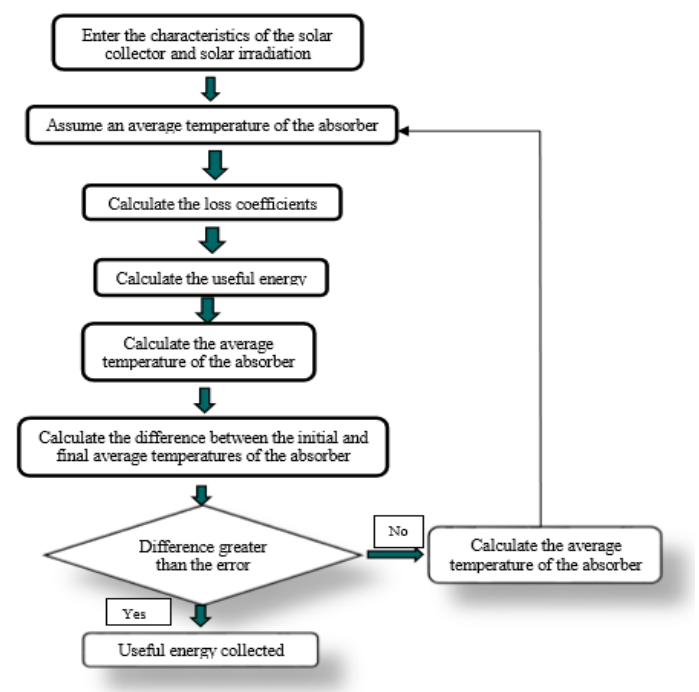

Figure1:- Simulation flowchart

\section{Results and Discussion:-}

In this part, we present, compare and analyze the results from our simulation work and experimental measurements. The experimental results presented in this section are the most complete among the series of manipulations we have made. They come from the manipulations of the 30/09/2016 and the 04/10/2016 carried out on the site of the Solar Energy Laboratory between 9 AMand 5PM, local time. For the results obtained from thesimulation, we used experimentally measured irradiation for each of the dates of our manipulation in the Matlab program that we developed on the basis of theequations presented above. The main physicalquantities that are the subject of our results are the solar irradiation, the outlet temperature of the water and the useful power received by the water.

For the flow computation experimentally, the following equation was used:

$$
q_{u}=m c_{p}\left(T_{s}-T_{e}\right)
$$

In order to verify if the model used to obtain our physical magnitudes is valid, we calculated the correlation coefficient $\mathrm{R}^{2}$ from the equation (38) established by Zhou et al [13]

$$
R^{2}=1-\frac{\sum\left(y_{i}-\hat{y}\right)^{2}}{\sum\left(y_{i}-\bar{y}\right)^{2}}
$$

With $y_{i}$ the measured experimental value, $\bar{y}$ the average value and $\hat{y}$ the calculated theoretical value.

To better compare the results, we have plotted on a single graph the experimental and theoretical curves for temperature and useful power.Here are the curves obtained. 
Results of the day of 30/09/2016:-

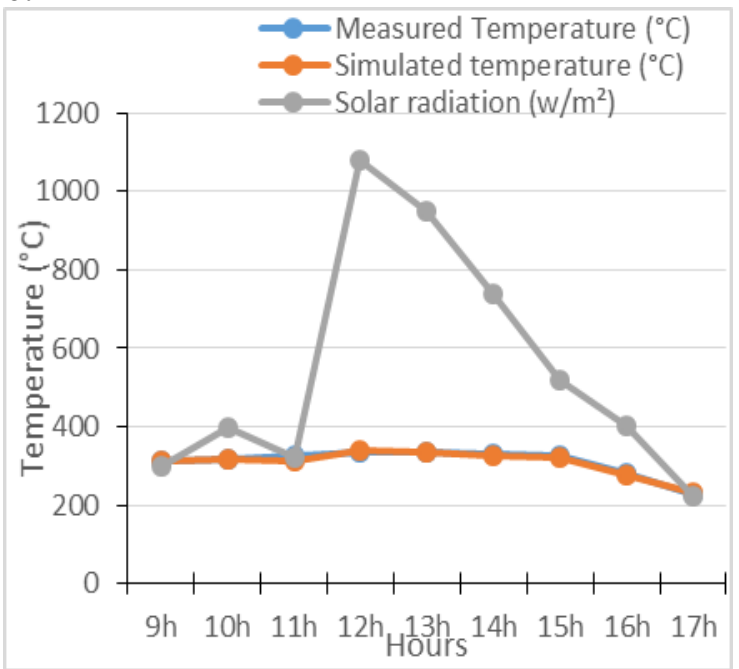

Figure 2:-Comparison between simulated andmeasured values of temperature.

The figure 2 shows the comparison between the simulated and experimental curves of the temperature evolution of 09/30/2016. The analysis of the results shows that at the level of the curve, there is a good concordance. The simulated values are very close to the experimental values. The correlation coefficient is 0.84 for both types of temperature. This value is close to 1 , it is deduced that the model used is valid for the estimation of the temperature.

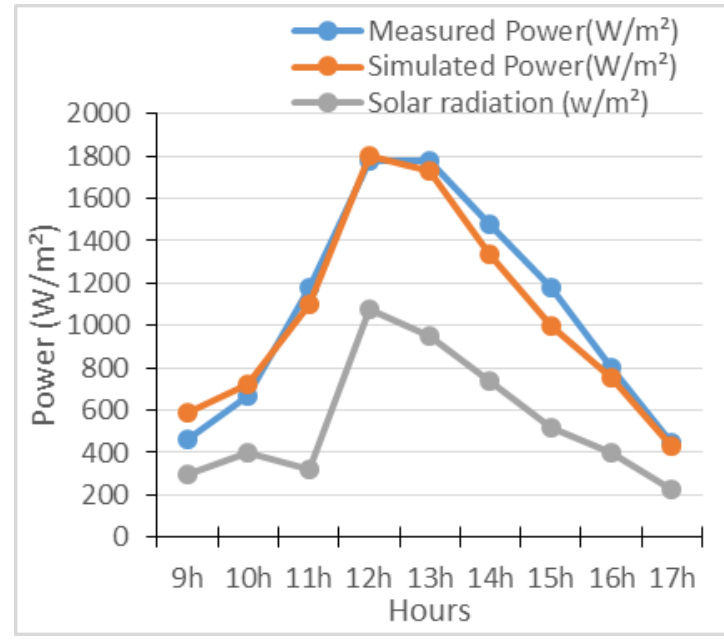

Figure 3:-Comparison between simulated andmeasured values of useful power

The figure 3 shows the simulation and experimentation curves of the useful power. The variations observed in this figure show that solar irradiation is an important factor. The two types of powers, although slightly different, perform the same types of variations. The correlation coefficient for the two power curves is 0.88 and close to 1 (one). This result allows us to conclude, as in the context of the temperature for the same day, that the model used is valid for estimating the useful power of solar water heaters in Togo.

\section{Results of the day of 04/10/2016:-}

Figure 4 shows that the temperature simulated on 04/10/2016 has variations similar to those obtained experimentally.The small differences observed can be explained by the non-consideration of thermal inertia in theory and the effect of cloud passage. In the same way, the useful power also undergoes the same effects of the thermal inertia. 


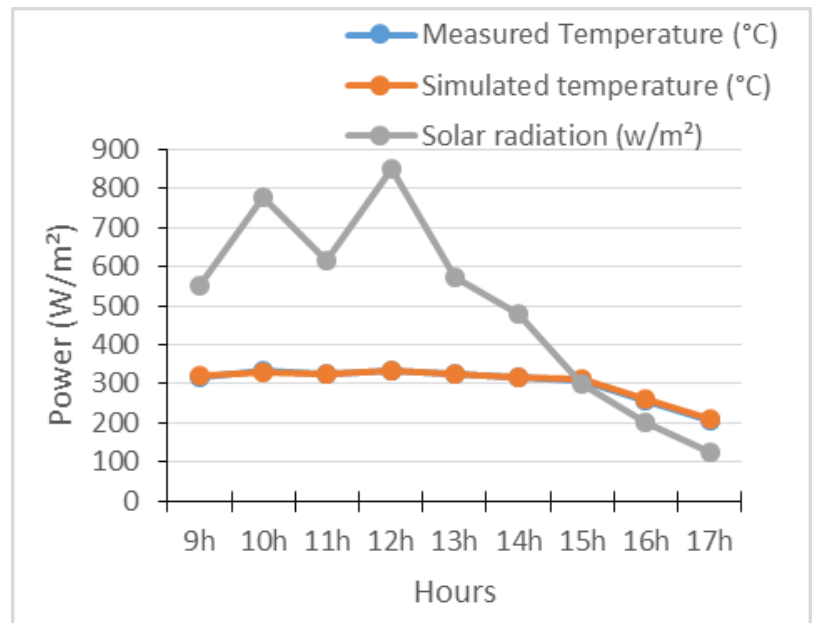

Figure 4:-Comparison between simulated and measured values of temperature.

Figure 4shows the two types of temperatures. The correlation coefficient is 0.82 . This value is less important than the first but close to 1 (one). It confirms the similarity observed in Figure 4. These results validate the model used to estimate the exit temperature of water from a solar water heater in Togo.

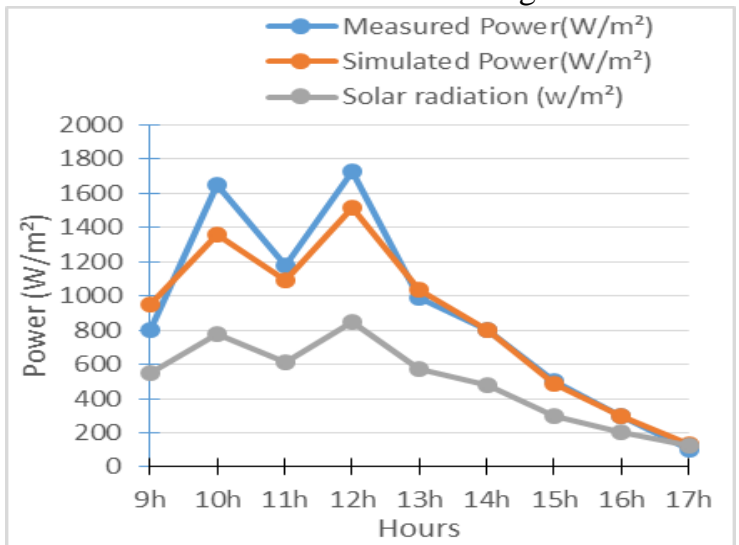

Figure 5: Comparison between simulated and measured values of temperature.

Figure 5 shows the power curves for the day of 04/10/2016. The correlation coefficient for these simulated and experimental power curves is 0.81 . We deduce that this model is valid as for the day of 30/09/2016.

\section{Conclusion:-}

During our simulation works, we came to estimate by modeling the water temperature at the outlet of the solar collector as well as the useful energy flow. An experimental work allowed to validate the theoretical results. The concordant results obtained between the theoretical and measured values prove that solar water heaters have the advantage of using the inexhaustible resource of energy that is the sun. This technology does not pollute or emit greenhouse gases. That is why this study falls within the framework of finding alternatives to the problem of energy and climate change. But the variability of the solar resource was the real problem encountered in this study. Given the ever increasing demand for firewood in Togo for water heating in hospitals and clinics as well as at the domestic level, the popularization of solar water heaters can validlybe a sustainable solution to deforestation.

\section{Nomenclature:-}

$A_{a}:$ absorber area (m2)

$A_{c}$ : total collector aperture area $\left(\mathrm{m}^{2}\right)$

$b$ : Bond width $(m)$

$C_{1}$ : first-order coefficient of the collector efficiency $\left(\mathrm{W} / \mathrm{m}^{2}{ }^{\circ} \mathrm{C}\right)$

$\mathrm{C}_{2}$ : second-order coefficient of the collector efficiency $\left(\mathrm{W} / \mathrm{m}^{2}{ }^{\circ} \mathrm{C}^{2}\right)$ 
C: collector concentration ratio $\frac{A_{a}}{A_{r}}$

$C_{p}$ : specific heat at constant pressure $(J / k g . k)$

$D$ : riser tube outside diameter $(\mathrm{m})$

$F$ : fin efficiency, cash flow

$F_{R}$ : heat removal factor

$h_{w}$ : wind heat transfer coefficient $\left(W / m^{2}{ }^{\circ} \mathrm{C}\right)$

$i$ :inflation rate (\%) I total horizontal radiation per unit area $\left(\mathrm{W} / \mathrm{m}^{2}\right)$

$\mathrm{K}$ :absorber thermal conductivity $\left(\mathrm{W} / \mathrm{m}^{\circ} \mathrm{C}\right)$

$\mathrm{k}$ : at incidence angle modifier $W / \mathrm{m}^{2}{ }^{\circ} \mathrm{C}$ )

$L$ : half distance between two consecutive riser piper

$m$ : mass flow rate of fluid $(\mathrm{kg} / \mathrm{s})$

$M$ : mass flow number

$N$ : days in month, number of years

$N_{g}$ : number of glass covers

$q_{u}$ : rate of useful energy delivered by the collector (W)

$q_{u}^{\prime}$ : useful energy gain per unit length $(\mathrm{J} / \mathrm{m})$

$q_{\text {fin }}^{\prime}$ : useful energy conducted per unit fin length $(\mathrm{J} / \mathrm{m})$

$q_{\text {tube }}^{\prime}$ : useful energy conducted per unit tube length $(\mathrm{J} / \mathrm{m})$

$Q$ : rate of heat transfer output (W)

$Q_{t}$ : thermal losses from the balloon

$Q_{u}$ : useful energy of the balloon

$R$ : receiver radius $(\mathrm{m})$

$S$ : absorbed solar energy $(\mathrm{kJ} / \mathrm{m} 2)$

$T$ : absolute temperature $(\mathrm{K})$

$T_{a}$ : ambient temperature $\left({ }^{\circ} \mathrm{C}\right)$

$T_{a v}$ : average collector fluid temperature $\left({ }^{\circ} \mathrm{C}\right)$

$T_{f}$ : localfluid temperature $\left({ }^{\circ} \mathrm{C}\right)$

$T_{f i}$ : temperatures of the fluid entering the collector $\left({ }^{\circ} \mathrm{C}\right)$

$T_{i}$ : temperatures of the fluid entering the collector $\left({ }^{\circ} \mathrm{C}\right)$

$T_{p}$ : average temperature of the absorbing surface $\left({ }^{\circ} \mathrm{C}\right)$

$U o$ : heat transfer coefficient from fluid to ambient air $\left(\mathrm{W} / \mathrm{m}^{2}{ }^{\circ} \mathrm{C}\right)$

$W$ : distance between riser tubes $(\mathrm{m})$, wind velocity $(\mathrm{m} / \mathrm{s})$

Greek symbols

$\tau \alpha$ : transmittance-absorptance product

$\alpha$ : fraction of solar energy reaching surface that is absorbed, absorptivity

$\beta$ : incidence angle (degrees), collector slope (degrees), misalignment angle error (degrees)

$\delta$ : absorber (fin) thickness ( $\mathrm{m})$, declination angle (degrees)

$\Delta t$ : temperature difference $(T i-T a)$

$\Delta x$ : elemental fin or riser tube distance (m)

\section{References:-}

1. A.C. Yunus and A.B. Michael, Thermodynamics: An engineer ing.approach. 20 Endalew, Numerical Modeling and experimental validation of Heat Pipe Solar collector for water heating, 2012.

2. F. Mosallat, T. Elmekkawy, D. Lepp, T. Molinski, S. Loney, and E.L. Bibeau, Modeling, simulation and control of flat panel solar collectors with thermal storage for heating and cooling applications, ProcediaProcediaComput. Sci., vol.19, no.seit, pp.686-693, 2013

3. F. Yettou, A. Gama, C. Hamouda, A. Malek, Etude et réalisation d'un banc d'essai pour un chauffe-eau solaire à circulation forcée dans la region des hauts plateaux, Rev des Energies renouvelables, vol.11, no 1,pp 119-128, 2008.

4. G.R. Hartwig and A.B. Sebitosi, Design of a solar powered desalination system for use in South Africa, Stellenbosch University, 2010.

5. H.Taherian, A. Rezania, S.Sadeghi, and D.D. Ganji, Experimental validation of dynamic simulation of the flat plate collector in a closed thermosiphon solar water heater, Energy convers. Manag.,vol.52, no.1,pp.301-307, 2011. 
6. J.A. Duffie and W.A. Beckman, Solar engineering of thermal processes, vol. 3 Wiley New York, 1980.

7. J.M. Therasammal and T. Bruno, Analysis of the Impact of solar thermal water heaters on the electrical distribution Load, Virginia Tech, 2011.

8. M.S. Hossain, R. Saidur, H. Fayaz, N.A. Rahim, M.R. Islam, J.U. Ahamed, M.M. Rahman, Review on solar water heater collector and thermal energy performance of circulating pipe, Renew, Sustain Energy Rev, vol.15, no.8,pp3801-3812, 2011.

9. O. A. Akintola and A.Y. Sangodoyin, Design, development and performance evaluation of solar heating system for disinfection of domestic roof-harvested rainwater, 2014.

10.S.A. Kalogirou, solar thermal collectors and applications, Prog. Energy combust. Sci, vol.30, no.3,pp 231295,2004

11.V.Dwivedi, Thermal modelling and control of domestic Hot water tank, no. 200858672, 2009.

12.W. Zhou, Applied a novel model for photovoltaic array performance prediction, vol.84, pp. 1187-1198, 2007

13. Y. A. Cengel and M.A. Boles, Thermodynamics: an engineering approach, Sea, vol.1000, p.8862, 1994

14. Y.A. Boles, Thermodynamics: An Engineering Approach, Fith. McGraw-Hill, 2006. 